\title{
The Saskatchewan rural health study: an application of a population health framework to understand respiratory health outcomes
}

Punam Pahwa ${ }^{1,2^{*}}$, Chandima P Karunanayake ${ }^{1}$, Louise Hagel ${ }^{1}$, Bonnie Janzen², William Pickett ${ }^{1,3,4}$, Donna Rennie ${ }^{1,5}$, Ambikaipakan Senthilselvan ${ }^{6}$, Josh Lawson', Shelley Kirychuk' and James Dosman ${ }^{1}$

\begin{abstract}
Background: Respiratory disease can impose a significant burden on the health of rural populations. The Saskatchewan Rural Health Study (SRHS) is a new large prospective cohort study of ages 6 and over currently being conducted in farming and non-farming communities to evaluate potential health determinants associated with respiratory outcomes in rural populations. In this article, we describe the rationale and methodology for the adult component.

The study is being conducted over 5 years (2009-15) in two phases, baseline and longitudinal. The baseline survey consists of two components, adults and children. The adult component consists of a questionnaire-based evaluation of individual and contextual factors of importance to respiratory health in two sub populations (a Farm Cohort and a Small Town Cohort) of rural families in Saskatchewan Rural Municipalities (RMs). Clinical studies of lung function and allergy tests are being conducted on selected sub-samples of the two cohorts based on the positive response to the last question on the baseline questionnaire: "Would you be willing to be contacted about having breathing and/or allergy tests at a nearby location?". We adopted existing population health theory to evaluate individual factors, contextual factors, and principal covariates on the outcomes of chronic bronchitis, chronic obstructive pulmonary disease, asthma and obstructive sleep apnea.

Findings: Of the RMs selected to participate, 32 (89\%) out of 36 RMs and 15 (94\%) out of 16 small towns within the RMs agreed to participate. Using the mail out survey method developed by Dillman, we obtained completed questionnaires from 4264 households (8261 individuals). We obtained lung function measurements on 1609 adults, allergy skin test information on 1615 adults; both measurements were available on 1549 adults. We observed differences between farm and non-farm rural residents with respect to individual, contextual factors and covariates.

Discussion: There are differences between farm and non-farm rural residents with respect to individual and contextual factors and other variables of importance. The findings of the SRHS will improve knowledge of respiratory disease etiology, assist in the development and targeting of prevention programs, and in planning health services with farm and small town populations.
\end{abstract}

Keywords: Rural, Respiratory, Asthma, Chronic bronchitis, Population health framework, Pulmonary function, Contextual

\footnotetext{
* Correspondence: pup165@mail.usask.ca

${ }^{1}$ Canadian Centre for Health and Safety in Agriculture, Royal University

Hospital, University of Saskatchewan, 103 Hospital Drive, Saskatoon, SK S7N

ow8, Canada

${ }^{2}$ Department of Community Health and Epidemiology, University of

Saskatchewan, Health Science Building, 107 Wiggins Road, Saskatoon, SK S7N

5E5, Canada

Full list of author information is available at the end of the article
} 


\section{Findings}

\section{Background}

Of all Canadian provinces, Saskatchewan has a one of the largest proportion of rural dwelling people (35\%) $[1,2]$. An increased prevalence of respiratory symptoms and decreased lung functions have been observed in a diverse group of male farmers compared to ruraldwelling non-farming male control subjects [3]. While much of this research has focused on swine and poultry workers [4-17], less is known about the respiratory status of more general populations of farming and nonfarming rural dwellers. It is known that farmers are exposed routinely to organic dusts, pesticides, diesel fumes, welding fumes and gases which increase their risks for acquiring respiratory health problems compared to other non-farming dwellers in rural areas [18-20]. In addition, unlike many other occupations, farming is an occupation where the workplace often overlaps with a residential environment. Accordingly, family members of farmers have increased opportunities for exposure to respiratory hazards, either directly or indirectly. Possible health effects of these exposures are not well documented for many farming and nonfarming rural populations. We developed the Saskatchewan Rural Health Study (SRHS) to address these gaps in knowledge.

The theoretical basis for the SRHS is the Population Health Framework (PHF) [21]. This framework provides a structure by which individual and contextual factors can be studied as possible determinants of respiratory health in farming and non-farming populations. A recent cohort study in our province has successfully utilized and tested this framework to evaluate the etiology of farm injuries [22]. Individual and contextual factors that could possibly lead to adverse respiratory health outcomes were identified based on historical evidence, both from our own research group and others [23-33].

Past research has demonstrated a relationship between exposure to pesticides and asthma in male farmers [23] and in farm women [24], which raises the possibility of a bystander effect and of gender-specific $[9,25]$ effects of exposures. Grain dust is made up of a number of components including grain parts and bacterial products, which may be involved in the genesis of lung dysfunction in grain dust exposures [26,27]. Respiratory outcomes are also related to bacterial products associated with dampness in homes [28-30], particularly in ruraldwelling women [31].

It has been shown that obesity is an issue in rural communities and is associated with reductions in pulmonary function that may affect women and men differently $[25,32,33]$. Thus, evidence suggests that determinants of respiratory health may be important for both farming and non-farming rural dwellers, that effects may be gender-specific, and that family members may be affected.

Although some evidence exists, additional evidence using a longitudinal survey approach is required to assess possible determinants of respiratory health among rural farming and non-farming people. In addition, most existing studies have been developed in the absence of an over-riding theory. Population health theory is one contemporary method from which to guide the systematic exploration of how individual and contextual risk factors influence respiratory health outcomes. To date, the respiratory health status and the determinants of respiratory health in farmers and their families and other rural dwellers have not been well established. The objective of this report is to describe the rationale, methodology, and descriptive results for a new cohort study of respiratory health among adults in rural Saskatchewan. The study aims to address observed gaps in the literature through the application of population health theory.

\section{Farm and non-farming cohorts}

The rural population is defined as consisting of those persons "living in towns and municipalities outside the commuting zone of larger urban centers with a population of 10,000 or more [34]." There are 50,598 farm enterprises in Saskatchewan encompassing 123,385 household residents [35].

Farm residence is defined as an area of land and its buildings (excluding the farm house) which normally produce agricultural commodities intended for sale. Non-farm residence is defined as a home on land that was not used for farming. Designation of residence in a rural dwelling and further classified as living on farm or non-farm based on the question 'Where is your home located?' with options: Farm, In town, Acreage. Town and acreage were combined to create a non-farm category, and this categorization was necessary because farming exposures are unique compared to non-farming exposures among rural residents.

\section{Materials and methods}

\section{Study design for adult baseline survey}

The SRHS design is a prospective cohort study being conducted in two phases, using a baseline survey and a five year follow-up study, each examining two study populations. At present, the baseline survey information has been collected. The baseline survey for adults consisted of three stages. The first stage involved recruitment of populations in rural municipalities (RMs) and small towns. The second stage consisted of administration of a mail household questionnaire to the target population. In the third stage, a sub-population participated in clinical assessments that involved anthropometric measures, lung function measurements, and allergy 
testing. The SRHS was conducted with the understanding and the informed consents of the all participants. The study was approved by the Biomedical Research Ethics Board of the University of Saskatchewan, Canada.

\section{Stage 1: community recruitment}

The southern half of Saskatchewan is organized into 297 RMs, each governed by an elected council which has the authority to levy taxes applied to landowners. Located within each of the RMs are incorporated towns and villages governed by an elected council that also have the authority to levy taxes. The study base consisted of tax paying households located in RMs and small towns in rural Saskatchewan. A multistage, stratified sampling strategy was used. First, the southern half of the province was divided into four quadrants (Northwest, Northeast, Southwest and Southeast) representing the diverse landscapes and industries in the province (Figure 1). Using the Statistics Canada definition of rural, a sector in each quadrant was identified for inclusion if it was located at least 60 kilometers from an urban center as defined by Statistics Canada [34]. A block of 12 adjacent RMs in each quadrant was identified. Selected RMs that had recently participated in another large cohort study [22] were excluded to avoid low participation rates due to study fatigue and in their place, adjacent RMs were selected.

Purposeful samples of 48 (12 from each quadrant) of the 297 rural municipalities (RMs) and 16 of the 145 towns (usual population 500 to 5000) in Saskatchewan were selected to participate in the study. A sample of 9 RMs was randomly generated for each quadrant. A member of the research team attended a regular meeting of each of the municipal councils for the 36 RMs and 16 small towns to recruit support for the project. The local councils for 32 (89\%) [9 from the Northwest, 8 from each of the Northeast and Southwest, and 7 from Southeast] of 36 RMs agreed to participate on behalf of their residents and supplied mailing addresses. Fifteen (94\%) [6 from the Northwest, 2 from the Northeast, 4 from Southwest, and 3 from Southeast] of 16 towns agreed to participate on behalf of their residents and also supplied mailing addresses. After excluding ineligible households (e.g. addresses unknown or outside study area, duplicates, deceased) $(\mathrm{n}=978)$, surveys were sent to 11,004 households.

\section{Stage 2: household recruitment}

A registry of mailing addresses was compiled from the taxation lists provided by the rural municipal and small town councils. Based on our sample size calculations to test associations, and assuming a 30\% response rate based on our previous study of RM populations [22] we sampled a population of 11,982 tax paying households (approximately 3000 per quadrant). A modified version of The Dillman Total Design Method for Mail and Telephone Surveys [36,37] was used in the administration of a baseline survey; this method was applied in order to maximize response rates. The Dillman method involves a series of mail contacts with all prospective participants. Mailings were addressed personally and sent via first class mail to all households in the database. Duplicate addresses and absentee home owners (those with addresses outside the study areas) were excluded. Study packages contained a letter of invitation, an information pamphlet, and the baseline questionnaire so that recruitment and data collection occurred simultaneously. A key informant in each household was asked to provide household level information and then to complete a section for each adult living in the household.

\section{Questionnaire development}

A panel consisting of the SRHS research team and two community members (one from a RM and one from a small town) developed the study questionnaire. The questionnaire was designed to include key measures required to test the population health framework (PHF) [21]. According to the PHF individual and contextual factors and the interaction between them may produce varying levels of risk for adverse respiratory health outcomes. More specifically, the SRHS aims to simultaneously evaluate individual factors (air quality, cigarette smoke, childhood chest infections, obesity), contextual factors (socio-economic, occupational history, past exposures, access to health services), and principal covariates on the respiratory health outcomes of chronic bronchitis, asthma, chronic obstructive pulmonary disease (COPD), and lung function measurements (see Figure 2). Covariates under study include demographic variables, selfperceived health status and co-morbid conditions, due to their association with an increased prevalence of chronic bronchitis, COPD, asthma and decreased lung function values [38].

A pilot study, described elsewhere [39], was conducted to optimize the content and administration of the baseline questionnaire. The RM and a small town which were used for the pilot study were not included in the baseline study. Based on the pilot project responses, several questions were modified in the questionnaire to be used for the baseline survey.

\section{Stage 3: clinical assessments}

The final question on the baseline questionnaire was 'Would you be willing to be contacted about having breathing and/or allergy tests at a nearby location?' Those who responded positively to this question were sent a letter of invitation to participate in a clinical 


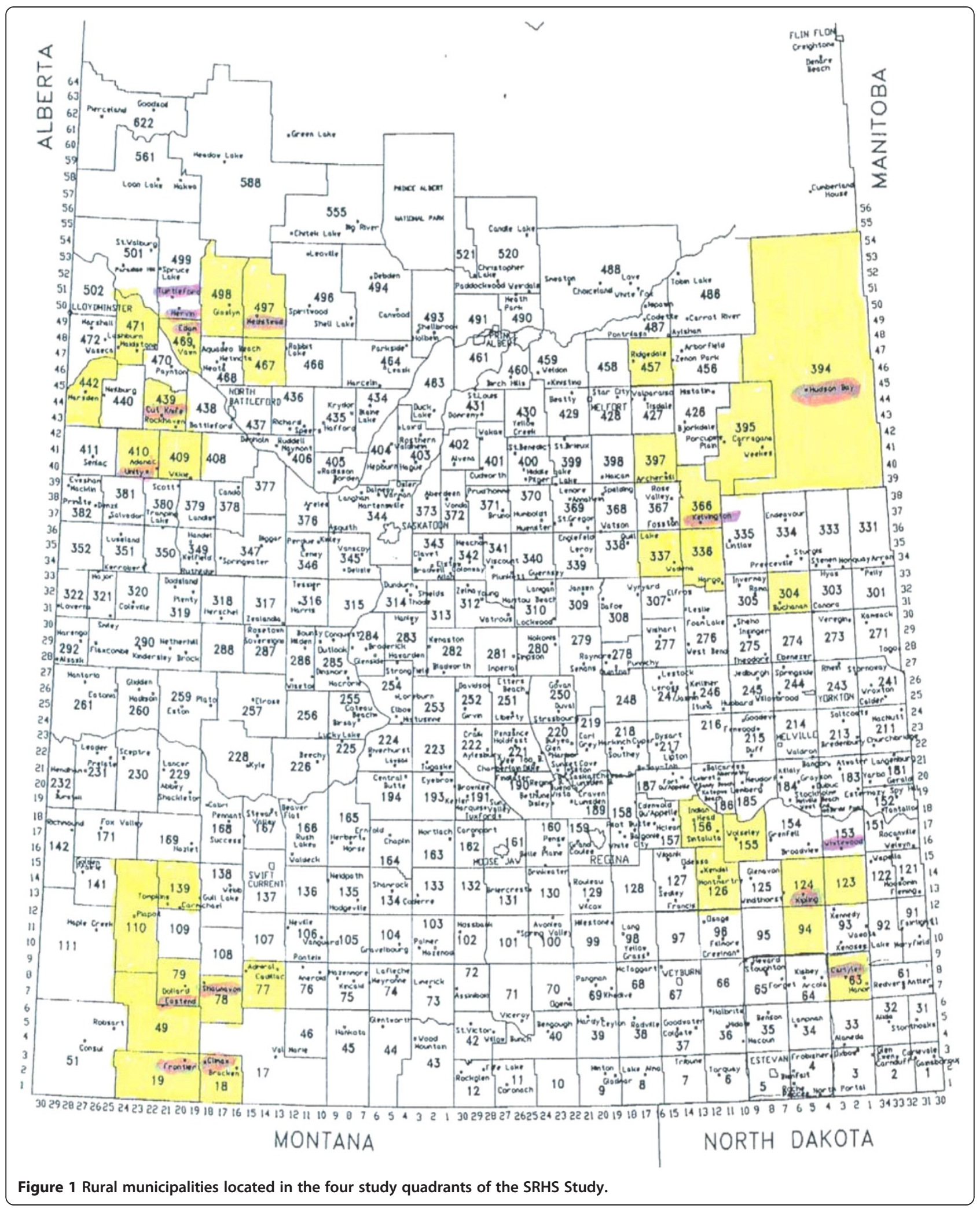




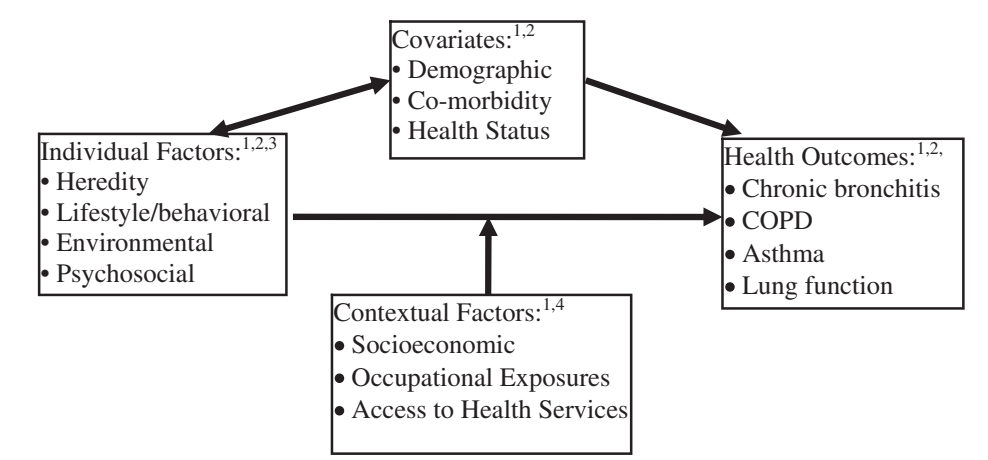

Legend of Assessment Methods: 1. Survey questionnaire; 2. Clinical assessments;

3. Environmental assessments; 4. Health care utilization records.

Figure 2 Conceptual Framework based on Population Health Framework of Health Canada (Diagram courtesy of Dr Will Pickett).

assessment. Research nurses trained in spirometry and allergy assessment and located in each study quadrant telephoned each household of consenting participants to arrange a time and a place (usually no greater than 60 kilometers from their residence) for this clinical assessment. Mobile clinics were set up in small towns located in the study area. Clinical measurements included the measurement of height and weight, blood pressure, forced expiratory capacity and allergy skin prick tests for six allergens. The protocol used to obtain these measurements is described below.

\section{Baseline clinical measurements}

Pulmonary function testing was conducted to obtain measures of forced expired volume in one second $\left(\mathrm{FEV}_{1}\right)$, forced vital capacity $(\mathrm{FVC}), \mathrm{FEV}_{1} / \mathrm{FVC}$ ratio, and maximum mid-expiratory flow rate $\left(\mathrm{FEF}_{25-75}\right)$. Sensormedics (Anaheim, CA) dry rolling seal spirometers were used for pulmonary function testing $[9,40,41]$. Measurements were taken according to standards of the American Thoracic Society criteria [42]. Percent predicted values for pulmonary function test variables were equated from the regression equations of Crapo et al. [43]. Allergy skin prick testing (SPT) was conducted using the skin prick method with a panel of six non-food allergens and two controls. Antigens used for testing were alternaria, house dust mite, cladosporium, local grasses, wheat dust, and cat dander. A positive (histamine) and negative (diluent) controls were used by methods as previously described [44]. Standardized allergen extracts were used as recommended by the Academy of Allergy, Asthma and Immunology [45]. SPT was performed according to the recommended protocol of practice parameters for Allergy, Asthma and Immunology and the American College of Allergy, Asthma and Immunology [45]. Subjects were considered positive for atopy if there was with a raised wheal greater than $3 \mathrm{~mm}$ compared to the saline control for one or more allergens tested. Quality of the lung function measurements data and skin prick testing was good as all spirometry measurements and skin prick testing were conducted by trained registered nurses.

\section{Variables of interest \\ Outcomes}

The information on respiratory health outcomes of asthma, chronic bronchitis, and chronic obstructive pulmonary disease (COPD) was ascertained from the survey questionnaire based on the following questions:

For asthma B-22 Have you ever had asthma?

Yes

No - > If no, go to question B-26.

B-23 If Yes to B-22:

Do you still have it? Yes No

Was it confirmed by a doctor? Yes No

At what age did it start? __ age in years

If you no longer have it, at what age did it stop? age in years

$\overline{B-24}$ If yes to B-22, how many times have you required services for asthma from the following places during the past 12 months?

Hospital inpatient: times

Emergency room outpatient: ___ times

Doctor's office: times

B-25 If yes to B-22, which of the following statements best describes your asthma medication use in the past 12 months

.Never in the past 12 months

.At least once in the past 12 months

.At least once per month

.At least once per week

.Every day 
For chronic bronchitis and COPD B-51 Has a doctor ever said you had any of the following chest illnesses:

- Chronic Bronchitis

- COPD (Chronic Obstructive Pulmonary Disease)

The information on COPD was ascertained from the questionnaire and as well as from the clinical pulmonary function tests.

\section{Contextual factors}

The contextual factors associated with respiratory health outcomes of interest in this study were residence location, socioeconomic status and indoor environment.

(i) Designation of residence in a rural dwelling and further classified as living on farm or non-farm based on the question 'Where is your home located?'. Details were given in the section 'Farm and non-farming cohort'.

(ii) Socioeconomic status was assessed using two questions. They were

(a) What is your best estimate of the total income, before taxes and deductions, of all household members from all sources in the past 12 months? .Less than $\$ 14,999$

. $\$ 15,000$ to $\$ 19,999$

$\$ 20,000$ to $\$ 29,999$

$\$ 30,000$ to $\$ 39,999$

$\$ 40,000$ to $\$ 49,999$

$\$ 50,000$ to $\$ 59,999$

. $\$ 60,000$ to $\$ 79,999$

$\$ 80,000$ or more

(b) At the end of the month, how much money do you have left over? (Please check only one)

Some money

Just enough money

.Not enough money

Household Income adequacy was a derived variable with four categories based on various combinations of total household income and the number of people living in the household according the Statistics Canada definition [46]. The description of the categories is given below.

The lowest income adequacy category consisted of income less than $\$ 15,000$ and household size of 1 or 2 persons, or total household income less than $\$ 20,000$ and household size of 3 or 4 persons, or total household income less than $\$ 30,000$ and household size of 5 or more persons. The lower middle income category consisted of total household income between \$15,000-\$29,999 and household size of 1 or 2 persons, or total lower income less than $\$ 20,000-\$ 39,999$ and household size of 3 or 4 persons, or total household income between $\$ 30,000-\$ 59,999$ and household size 5 or more persons. The upper middle income category consisted of total household income between $\$ 30,000-\$ 59,999$ and household size of 1 or 2 persons, or total lower income less than $\$ 40,000$ $\$ 79,999$ and household size of 3 or 4 persons, or total household income between \$60,000-\$79,999 and household size 5 or more persons. The highest income adequacy category consisted of $\$ 60,000$ or more and household size of 1 or 2 persons, or total income category was $\$ 80,000$ or more and household size of 3 persons or more.

(iii) Indoor environment was assessed by response to questions about dampness, mold, smoking inside the house, number of people and bedrooms, air conditioning, pets in home, pesticides applied inside home and fuel source. Information on dampness, mold and smoking inside the house was collected by the following three questions respectively: "During the past 12 months, has there been water or dampness in your home from broken pipes, leaks, heavy rain, or floods? (Yes/ No/Don't know)"; "Does your home (including basement) frequently have a mildew odor or musty smell? (Yes/No/Don't know)"; "Do any of the people who live in your house use any of the following tobacco products in the home? (Cigarettes: Yes/No/Don't know; Cigars: Yes/No/ Don't know; Pipes: Yes/No/Don't know)".

(iv) Information about the remaining contextual factors was collected using the following questions: "How many people live in your home? (This variable includes all persons including children who usually live in home)", "How many bedrooms do you have in your home?", "Does your home have air conditioning?", "In the past 12 months have you had any pets living in your home", "Within the past 12 months, were pesticides applied inside your residence (e.g. raid, spider bait, any bait, rat bait), and "Is natural gas primary fuel source to heat your home?".

(v) In addition information about access to health care in the past 12 months were collected using following questions: "Do you and your family members in your household have access to a regular family doctor or nurse practitioner?", In the past 12 months did you ever experience any difficulties getting the routine or on-going care for you or a family member in your household ", "In the past 12 months, have you required a visit 
to a medical specialist for a diagnosis or consultation for yourself or a family member in your household?", "In the past 12 months did you ever experience any difficulty getting the specialist care you needed for a diagnosis or consultation for yourself or a family member in your household?", "In the past 12 months, have you or a family member in your household required immediate 24 hour health care services for a medical emergency?", and "In the past 12 months, did you ever experience any difficulties getting immediate 24 hour health care services for a medical emergency for yourself or a family member in your household?".

\section{Individual factors}

The individual factors considered were: (i) individual educational attainment. The highest level of education (less than high school, completed high school, completed university, completed post-secondary education other than above) recoded into a new variable "Education" combining the first two levels ( $\leq$ grade 12$)$ and last two levels (> grade 12) for the analysis; (ii) lifestyle or behavior-related factors with an expected impact on health including smoking and physical activity; (iii) the general health status and co-morbid conditions such as diabetes, heart disease, heart attack, hardening of the arteries, high blood pressure and cancer; (iv) family history of respiratory health problems; among first degree relatives (father, mother, brother/sister) excluding offspring; and (v) environmental and occupational exposures. Information about environmental and occupational exposures was based on the question; "Have you ever been exposed to any of the following in your workplace? [the list included: grain dust, mine dust, asbestos dust, wood dust, other dust _ specify, livestock, smoke from stubble burning, diesel fumes, welding fumes, solvent fumes, oil/gas well fumes, herbicides (to kill plants), fungicides (to treat grain), insecticides (to kill insects), molds, radiation, Other — specify]; information was also collected on the frequency (Daily, Weekly, Monthly, Occasionally) and duration "How many years?" of usage.

\section{Covariates}

Information was obtained on covariates of importance such as age, sex, marital status, co-morbid conditions (allergy) and body mass index. Body mass index was derived from self-reported weight and height of the respondent. Response to the question "Have you ever had an allergic reaction to any of the following: house dust; cats; dogs; grasses; pollens; molds; other (specify)?" was used to assess allergic conditions.

\section{Sampling frame}

In order to accomplish the objective, we proposed to use a Sampling Frame of 5000 farm residents and 4000 Small Town residents living in isolated rural areas of four quadrants of the province.

Based on our experience in the Farm Injury Cohort Study [22], we conservatively predict a $65 \%$ response rate among the 5000 members of the Farm Cohort to have 3250 respondents to participate in the mail baseline questionnaire survey (Table 1). We proposed that the Small Town Cohort will be comprised of persons dwelling in small rural Saskatchewan communities, selected on a regional basis, with a collective population of 4000 persons. Of these we anticipated, conservatively, that $\sim 65 \%$, or 2600 persons would respond to the mail baseline questionnaire survey.

\section{Sample size calculations \\ Dichotomous outcome}

To compare prevalence of a respiratory condition between two groups, the sample size $[47,48]$ required to test the hypotheses was calculated based on the following modified formula [49]:

$n=\left[\frac{z_{a} \sqrt{2 \bar{p}}(1-\bar{p})+z_{\beta} \sqrt{p_{1}\left(1-p_{1}\right)+p_{2}\left(1-p_{2}\right)}}{d}\right]^{2} *[1+(\mathrm{m}-1) \rho]$

where $p_{1}$ (prevalence of respiratory condition in the Farm Cohort) and $p_{2}$ (prevalence of respiratory condition in the Small Town Cohort) are pre-study estimates of the two proportions to be compared, $d=\left|p_{1}-p_{2}\right|$ (i.e., the minimum expected difference), $\bar{p}=\left(p_{1}+p_{2}\right) / 2$, and we require $n$ subjects per group for type-I error $(\alpha)=$ 0.05 and power $(1-\beta)=0.80$. The adjustment was

Table 1 Proposed and Observed number of participants in Farm Cohort and Small Town Cohort for Baseline Study

\begin{tabular}{|c|c|c|c|c|}
\hline & \multicolumn{2}{|c|}{ Farm Cohort } & \multicolumn{2}{|c|}{ Small Town Cohort } \\
\hline & Proposed sample & Observed sample & Proposed sample & Observed sample \\
\hline Self-report questionnaire & 3250 & 4472 & 2600 & 3785 \\
\hline \multirow[t]{3}{*}{ Clinical measurements (25\%) } & 813 & Lung function, $\mathrm{n}=930$ & 650 & Lung function, $n=679$ \\
\hline & & Allergy test, $\mathrm{n}=929$ & & Allergy test, $n=686$ \\
\hline & & Both, $n=896$ & & Both, $n=653$ \\
\hline
\end{tabular}


incorporated by using the variance inflation factor $(V I F)$ to account for clustering within household, where $V I F=1$ $+(m-1) * \rho$ (where $\mathrm{m}=$ number of individuals per household assumed to be 2.4 , and $\rho=$ intra-class correlation coefficient for within subject clustering $=0.3,0.5$ ). The required sample sizes for selected values of $\mathrm{p}_{1}, \mathrm{p}_{2}$ are given in Additional file 1 Table S1. The proposed sample sizes of 3250 and 2600 in each of the groups are adequate for comparison in the total sample (see Table 1).

\section{Continuous outcomes}

To compare continuous respiratory outcome between two groups, the sample size $[50,51]$ required to test the hypotheses was calculated based on the following modified formula [49]:

$$
n=\frac{2 *\left(\mathrm{z}_{\mathrm{a}}+\mathrm{z}_{\beta}\right)^{2} \sigma^{2}}{d^{2}} *[1+(\mathrm{m}-1) \rho]
$$

To detect the smallest meaningful difference between the means of two groups, 'd' (e.g. Farm Cohort vs. Small Town Cohort), for a given standard deviation (assumed to be equal for both groups), $\sigma$, we require ' $n$ ' subjects per group for type-I error $(\alpha)=0.05$ and power $(1-\beta)=$ 0.80 . The required sample sizes for selected values of $\mu_{1}$, $\mu_{2}, \sigma$ to detect a minimum difference of ' $d$ ' between two groups to achieve $80 \%$ power are given in Additional file 2 Table S2. The adjustment was incorporated by using the variance inflation factor (VIF) to account for clustering within household, where VIF $=1+(m-1) * \rho$ (where $\mathrm{m}=$ number of individuals per household assumed to be 2.4 , and $\rho=$ intra-class correlation coefficient for within subject clustering $=0.3,0.5$ ). The proposed sample sizes of 3250 and 2600 in each of the groups are adequate for comparison in the total sample.

\section{Statistical analysis}

Response rates were first examined descriptively by rural RM and small town categories. Descriptive results comparing the characteristics of farming (living on a farm) and non-farming (living in a small town or on an acreage) populations are presented in this report. Statistical analysis was completed using IBM SPSS Statistics Version 19 (IBM Corporation, Armonk, New York). For baseline data, standard classical techniques, such as $\chi^{2}$ analysis techniques, t-tests and analysis of variance were utilized for descriptive group comparisons. Such comparisons were conducted for individual characteristics (e.g. age, income, smoking status), contextual factors (e.g. household income, number of people living in the household), other covariates and respiratory outcomes. The main purpose of this analysis was to demonstrate that we had sufficient variability in exposures, covariates and outcomes to achieve our main analytical goals.

\section{Results}

Of the RMs and small towns selected to participate, 32 (89\%) out of 36 RMs and 15 (94\%) out of 16 small towns agreed to participate. Questionnaires were mailed to 11,982 households located in four geographical regions (Northwest, Southwest, Southeast, and Northeast) of Saskatchewan, Canada in 2010. Of these, 978 addresses were excluded because ratepayers were not living in the area, they had moved, were deceased or address was a duplication or unknown.

Data were entered and cleaned on an ongoing basis. Final response rates are presented in Table 2 . The response rate to the mail-out survey was moderate (42\%), although it is uncommon to get a higher response rate for mail-out surveys without inducement. The participation rate for non-farm dwellers and farm dwellers were similar, $42.2 \%$ and $41.9 \%$ respectively. We obtained completed questionnaires from 4624 households (8261 individuals). Lung function measurements were completed for 1609 adults and allergy skin tests information was available for 1615 adults. Both measurements were available for 1549 adults. There were a significantly higher proportion of individuals older than 65 years in the north east quadrant compared to other quadrants (Table 3). Compared to north east quadrant, a higher proportion of individuals lived in non-farm locations in the other three quadrants (Table 3). Baseline descriptive results for selected individual and household factor, and selected covariates stratified by farm and non-farm locations are provided in Additional file 3 Tables S3 and Additional file 4 Table S4.

\section{Comparison of individual factors and covariates}

A higher prevalence of current smokers was found among non-farm population compared to the farm population, (13.5\% vs. $9.5 \%$ respectively). A higher proportion of the farm population reported very good (38.3\% vs. $33.2 \%$ respectively) to excellent (9.5\% vs. $8.5 \%$ respectively) self-perceived health compared to the nonfarm population. A significantly higher proportion of non-farm dwellers reported the presence of co-morbid conditions compared to the farm dwellers (diabetes: $10.9 \%$ vs. $7.1 \%$; heart disease: $8.9 \%$ vs. $5.7 \%$; heart attack: $5.2 \%$ vs. $3.0 \%$; hardening of the arteries: $3.9 \%$ vs. $2.8 \%$; high blood pressure: $36.1 \%$ vs. $30.2 \%$; cancer: $8.8 \%$ vs. $7.6 \%$ ). Compared to the non-farm dwellers, a significantly higher proportion of farm dwellers were exposed to various occupational exposures (grain dust: $86.7 \%$ vs. 54.6\%; wood dust: $45.4 \%$ vs. $33.5 \%$; livestock: $69.6 \%$ vs. 37.9\%; smoke stubble: $51.7 \%$ vs. $31.7 \%$; diesel fumes: $72.5 \%$ vs. $48.5 \%$; welding fumes: $52.8 \%$ vs. $32.5 \%$; solvents: $39.7 \%$ vs. $32.2 \%$; pesticides including herbicides: $66.6 \%$ vs. $38.9 \%$; fungicides: $44.3 \%$ vs. $24.4 \%$; insecticides: $56.3 \%$ vs. $36.7 \%$; and molds: $46.3 \%$ vs. $25.9 \%$ ). 
Table 2 Response rates achieved in Saskatchewan Rural Health Study in the $\mathbf{2 0 1 0}$ baseline survey

\begin{tabular}{|c|c|c|}
\hline Response to Mail Survey & Small Town & RM \\
\hline & $(n=15)$ & $(n=32)$ \\
\hline Household addresses (ratepayers) ${ }^{\#}$ & 5318 & 5683 \\
\hline \multicolumn{3}{|l|}{$(n=11004)$} \\
\hline Household Returned Surveys, n (\%) & $2800(52.7)$ & $2910(51.2)$ \\
\hline No Response, n (\%) & $2518(47.3)$ & $2773(48.8)$ \\
\hline Response rate (based on household addresses) & $2242(42.2)$ & $2380(41.9)$ \\
\hline \multicolumn{3}{|l|}{$(n=4624), n(\%)$} \\
\hline \multicolumn{3}{|l|}{ (Note: Two households were not identified) } \\
\hline Persons participating $(n=8261)$ & 3785 & 4472 \\
\hline \multicolumn{3}{|l|}{ (Note: four individuals were not identified by town/RM) } \\
\hline Age (mean \pm SE) & $56.3 \pm 0.28$ & $55.9 \pm 0.22$ \\
\hline \multirow[t]{2}{*}{ Male : Female ratio } & $1774 / 2007$ & $2292 / 2179$ \\
\hline & 0.88 & 1.05 \\
\hline \multicolumn{3}{|l|}{ Clinical assessments $(n=1675)$} \\
\hline Lung function, n (\%) & $679(40.4)$ & $930(55.3)$ \\
\hline Allergy Test, n (\%) & $686(40.8)$ & 929 (55.3) \\
\hline Both, $n(\%)$ & 653 (38.8) & 896 (53.3) \\
\hline
\end{tabular}

\section{Comparison of contextual factors}

A higher proportion of households on farm locations had 2 or more people $(28.0 \%)$ and 3 or more bedrooms (44.2\%) compared to households on non-farm locations ( $\geq 2$ people $-22.9 \%$, and $\geq 3$ bedrooms-32.6\%). Dampness and mildew odor were significantly more prevalent in houses located on farms compared to those on non- farms. The proportion of pesticides applied inside home was significantly higher in houses located on farms compared to those on non-farms. The proportion of use of tobacco in homes was higher in houses located on nonfarm locations compared to those located on farms. Three household income variables (Total household income, household income adequacy, and Money left at

Table 3 Populations characteristics by quadrant

\begin{tabular}{|c|c|c|c|c|c|}
\hline \multirow[t]{4}{*}{ Characteristics } & \multicolumn{4}{|c|}{ Quadrant $^{\#}$} & \multirow[t]{4}{*}{$P$ value } \\
\hline & South West & South East & North East & North West & \\
\hline & $\mathrm{N}=\mathbf{8 7 8}$ & $N=1010$ & $\mathrm{~N}=1315$ & $N=1419$ & \\
\hline & $n=1538$ & $n=1792$ & $\overline{n=2400}$ & $n=2527$ & \\
\hline \multicolumn{6}{|c|}{ Rural Municipality, n (\%) } \\
\hline Town & $691(44.9)$ & $921(51.4)$ & $1622(67.6)$ & $1238(49.0)$ & $<0.0001^{* * *}$ \\
\hline $\mathrm{RM}$ & $847(55.1)$ & $871(48.6)$ & $778(32.4)$ & $1289(51.0)$ & \\
\hline \multicolumn{6}{|c|}{ Location of Home, n (\%) } \\
\hline Farm & $552(36.0)$ & $704(39.6)$ & $1192(50.0)$ & $997(39.7)$ & $<0.0001^{* * *}$ \\
\hline Non-Farm & $980(64.0)$ & $1072(60.4)$ & $1193(50.0)$ & $1514(60.3)$ & \\
\hline \multicolumn{6}{|l|}{ Age group, yrs, n (\%) } \\
\hline $18-45$ & $341(22.2)$ & $464(25.9)$ & $485(20.2)$ & $647(25.6)$ & $<0.0001^{* * *}$ \\
\hline $46-55$ & $433(28.2)$ & $441(24.6)$ & $552(23.0)$ & $620(24.6)$ & \\
\hline $56-65$ & $319(20.8)$ & $422(23.5)$ & $599(25.0)$ & $608(24.1)$ & \\
\hline$>65$ & $444(28.9)$ & $465(25.9)$ & $762(31.8)$ & $650(25.7)$ & \\
\hline \multicolumn{6}{|l|}{ Sex, n (\%) } \\
\hline Male & $750(48.8)$ & $886(49.4)$ & $1201(50.0)$ & $1229(48.7)$ & 0.791 \\
\hline Female & $788(51.2)$ & $906(50.6)$ & $1199(50.0)$ & $1293(51.3)$ & \\
\hline
\end{tabular}

$\# N=$ Number of households; $n=$ number of individuals; Four individuals in 2 households could not identified.

${ }^{*} \mathrm{p}<0.05{ }^{* *} \mathrm{P}<0.01{ }^{* * *} \mathrm{P}<0.0001$. 
end of month) were significantly related to the residence status of farm/non-farm. It is observed that higher proportion of farm households reported highest income.

\section{Discussion}

The SRHS is a large, prospective cohort study based on a modified conceptual framework of the PHF that was successfully used as a framework for a related injury cohort study [22]. The purpose of the SRHS is to test the hypothesis that rural environments, as determinants of health, are associated with respiratory outcomes in farming and non-farming rural people. To our knowledge, no other Canadian study has been conducted to investigate the health determinants of respiratory health among rural people in this manner. Hence, the results of this study will contribute to understanding the health determinants of respiratory health status among rural farming and non-farming people. The complex methodological approach used in this study captured many factors associated with variability found in rural populations. Appropriate statistical methods that account for the nested and hence clustered nature of the sampling design (individuals nested within households, nested within RMs) will be utilized to test the major hypothesis for four primary respiratory health outcomes: chronic bronchitis, asthma, COPD, and lung function measurements. Based on our preliminary findings, quadrant level, location of home (farm versus non-farm) and sex will be examined in all future analyses.

This manuscript reports the results derived from the baseline data on farming and non-farming adults. The statistical analyses were conducted to compare demographic characteristics, individual and contextual factors, and important covariates among farming and nonfarming people. As shown in Additional file 3 Table S3 non-farming residents were significantly older than farming residents in rural Saskatchewan. Fifty-two percent of residents were males in farming locations compared to $47.2 \%$ male residents in non-framing locations. Significantly higher number of farm residents were either married or lived as a common-law, or living together compared to non-farming residents. No difference was observed in the BMI distribution between farming and non-farming residents.

Compared to non-farming residents, a higher proportion of farming residents reported to be in excellent or very good health. A higher proportion of co-morbid conditions (diabetes, heart disease, heart attack, hardening of the arteries, high blood pressure, cancer) were observed in non-farming population.

There is limited literature available for comparison of our results and the definitions of farm and non-farm residents vary. The Wisconsin Rural Women's Health Study reported that the prevalence of current smoking was significantly higher among non-farm women residents [52]. Also, the same study reported that the prevalence of hypertension and obesity was significantly higher among farm women residents [52]. In contrast to that for both men and women, we observed significantly higher prevalence in current smoking in the non-farm residents. Both non-farm men and women in our study reported significantly higher prevalence of obesity and co-morbid conditions including diabetes, heart disease, high blood pressure, lung disease and cancer.

The Iowa farm and non-farm household study reported greater pesticides exposure among farm residents compared to non-farm residents [53]. Another study of children of Iowa farmers and non-farmers reported a significantly higher pesticide exposure among farm children [54]. We also observed that a higher proportion of farm residents were ever exposed to pesticides (herbicides, fungicides and insecticides). Also significantly a higher proportion of farm-residents applied pesticides inside their homes compared to non-farm residents.

We observed that farm residents had a significantly higher household income level compared to non-farm residents. Similar to this Stiefelmeyer reported that on an average, total farm family income exceeds that of rural non-farm counterparts in Canada [55].

A study examining the importance of place of residence on use of health services observed that nonmetropolitan elderly, both farm and non-farm, make fewer physician visits than do their metropolitan counterparts [56]. Also they reported significantly fewer physician visits for nonmetropolitan farm residents compared to nonmetropolitan non-farm residents [56]. In our study we found no differences in physician visits between farm and non-farm residents.

\section{Strengths and limitations of the SRHS}

There are several major strengths to this study. A large sample size will provide adequate statistical power to test the major statistical hypothesis and several secondary hypotheses to investigate various etiologies of respiratory health, as evident in our descriptive analyses presented here. Extensive information has been obtained on individual and contextual factors and important covariates via self-administered mail-out questionnaires and clinical and allergy tests on a self-selected group of study participants. The population studied live in widespread locations in the four quadrants of the province representing a wide range of geographical areas in Saskatchewan. Hence a mail questionnaire survey was the best option for us. Other authors have discussed this issue and they have concluded that with the increasing cost of interviewing, a mail questionnaire surveys in widely spread geographical areas was the best $[37,57]$. Our team 
consists of researchers from multi-disciplinary areas bringing a comprehensive set of perspectives on the topic of respiratory health in two rural cohorts.

One of the limitations of our study is that the rural areas examined have either no metropolitan influence zone (MIZ), or weak or moderate MIZ. There was no RM or small town with a strong MIZ. This indicates that our study population may not be representative sample of Saskatchewan rural population. Therefore, it is necessary to be cautious in generalizing our results related to the respiratory health outcomes (based on future analyses) to the entire Saskatchewan rural population. However, we may be able to generalize our results for rural areas with no, weak, or moderate MIZ.

Since Saskatchewan remains a considerably rural province, the information resulting from this project will assist in prevention programs and in planning for respiratory health service delivery to rural areas. Identification of factors that promote health and prevent disease in rural populations will help to inform strategies used to improve disease outcomes, including more effective public education programs and more rationally conceived health services delivery strategies. The findings from this study will help to inform policy in Saskatchewan at the Regional Health Authorities level, in addition to helping shape and determine national and provincial health services priorities.

\section{Future directions of the SRHS}

Phase 2, which will commence in 2014, will consist of a longitudinal survey follow-up of individuals who participated in the baseline survey. In order to maintain the high retention rate in our follow-up study, we will be in touch with the study populations, and RM and small town councilors via regular local newsletters, local newspapers, presentation of results at RM and small town council meetings, the project website (under construction) and other effective communication media.

The longitudinal component will consist of a followup questionnaire through which we will acquire data on principal individual and contextual factors of importance to respiratory health in farming and non-farming rural people in Saskatchewan, and clinical studies of principal lung function measurements and allergy tests as outlined above for the baseline survey. In our future articles, based on the Population Health Framework [22], we will test the overall hypothesis that rural environments as determinants of health are associated with respiratory outcomes in rural people.

\section{Conclusions}

There are differences between farm and non-farm rural residents with respect to individual and contextual factors; and other variables of importance. The association of these factors with primary respiratory health outcomes in SRHS might be different in farm and non-farm populations. We will be exploring these associations in our future manuscripts. The findings of the SRHS will improve knowledge of respiratory disease etiology, assist in the development and targeting of prevention programs for rural population of Saskatchewan. The information resulting from this project will assist in planning health services delivery for farm and small town populations.

\section{Additional files}

Additional file 1: Table S1. Sample size required per group for selected values of $p_{\mathbf{1}}, \mathbf{p}_{\mathbf{2}}$ and $\mathbf{d}$. Description: Sample size required per group for selected values of $p_{1}, p_{2}$ and $d$ comparing two proportions.

Additional file 2: Table S2. Sample size required per group to detect a minimum difference, $d$ between two groups for selected values of $\sigma$. Description: Sample size required per group to detect a minimum difference, $d$ between two groups for selected values of $\sigma$ for comparing continuous outcomes.

Additional file 3: Table S3. Comparison of baseline individual factors and covariates of farm and non-farm people participating in the SRHS. Description: Descriptive comparison of baseline individual factors and covariates of farm and non-farm people participating in the SRHS.

Additional file 4: Table S4. Comparison of household covariates and household factors of farm and non-farm people participating in the Saskatchewan Rural Health Study.Description: Descriptive Comparison of household covariates and household factors of farm and non-farm people participating in the Saskatchewan Rural Health Study.

\section{Abbreviations}

SRHS: Saskatchewan Rural Health Study; RM: Rural Municipality; PHF: Population Health Framework; FEV ${ }_{1}$ : Forced Expired Volume in one second; FVC: Forced Vital Capacity; FEF $_{25-75}$ : Maximum mid-expiratory flow rate; SPT: Skin Prick Testing.

\section{Competing interests}

All authors declare that they have no competing interests.

\section{Authors' contributions}

All authors contributed to grant writing, development of study design, questionnaire development, and study coordination. JAD and PP are the coprincipal investigators of the SRHS study. CPK is the biostatistician and she supervised every stage of data entry and data cleaning and conducted the statistical analyses. LH is the project manager. PP prepared the manuscript and JAD, WP, DR, LH and CPK significantly contributed to manuscript preparation. All authors read and approved the final manuscript.

\section{Acknowledgements}

This study was funded by a grant from the Canadian Institutes of Health Research "Saskatchewan Rural Health Study", Canadian Institutes of Health Research MOP-187209-POP-CCAA-11829. We are grateful for the contributions of all the participants who donated their time to complete and return the survey.

\section{Author details}

${ }^{1}$ Canadian Centre for Health and Safety in Agriculture, Royal University Hospital, University of Saskatchewan, 103 Hospital Drive, Saskatoon, SK S7N OW8, Canada. ${ }^{2}$ Department of Community Health and Epidemiology, University of Saskatchewan, Health Science Building, 107 Wiggins Road, Saskatoon, SK S7N 5E5, Canada. ${ }^{3}$ Department of Community Health and Epidemiology, Queen's University, Carruthers Hall, Kingston, ON K7L 3N6, Canada. ${ }^{4}$ Accident Research Centre, Monash University, Building 70, Victoria 3800, Australia. ${ }^{5}$ College of Nursing, University of Saskatchewan, 107 Wiggins 
Road, Saskatoon, SK S7N 5E5, Canada. ${ }^{6}$ Public Health Sciences, School of Public Health, University of Alberta, 3-50 University Terrace, 8303-112 Street, Edmonton, AB T6G 2T4, Canada.

Received: 24 January 2012 Accepted: 13 July 2012

Published: 1 August 2012

\section{References}

1. Statistics Canada: Population, Urban and Rural by province and territorySaskatchewan, Census of population 1851-2006.: ; Accessed on July 25, 2011, Available from http://www40.statcan.gc.ca/l01/cst01/demo62i-eng.htm.

2. Statistics Canada: Population, Urban and Rural by province and territoryCanada, Census of population 1851-2006. Accessed on July 25, 2011, Available from http://www40.statcan.gc.ca/l01/cst01/demo62a-eng.htm.

3. Dosman JA, Graham BL, Hall D, Loon PV, Bhasin P, Froh F: Respiratory symptoms and pulmonary function in farmers. J Occup Med 1987, 29:38-43.

4. Dosman JA, Senthilselvan A, Lemay S, Kirychuk SP, Barber ME, Willson P, Cormier $Y$, Hurst TS: Positive human health effects of wearing a respirator in a swine barn. Chest 2000, 118(3):852-860

5. Cormier Y, Duchaine C, Israel-Assyag E, Bedard G, Laviolette M, Dosman J: Effects of swine building exposures on normal naïve subjects. Eur Respir 1996, 10(7):1516-1522

6. Zejda JE, Hurst TS, Rhodes CS, Barber EM, McDuffie HH, Dosman JA Respiratory health of swine producers. Focus on young workers. Chest 1993, 103:702-709.

7. Senthilselvan A, Dosman JA, Kirychuk SP, Barber EM, Rhodes CS, Zhang Y Hurst TS: Accelerated lung function decline in swine confinement workers. Chest 1997, 111:1733-1741.

8. Kirychuk S, Senthilselvan A, Dosman JA, Zhou C, Barber EM, Rhodes C, Hurst T Predictors of longitudinal changes in pulmonary function among swine confinement workers. Can Resp J 1998, 5(6):472-478.

9. Senthilselvan A, Chenard L, Ulmer K, Gibson-Burlinguette N, Leuschen C, Dosman JA: Excess respiratory symptoms in full-time male and female workers in large-scale swine operations. Chest 2007, 131(4):119-204.

10. Kirychuk SP, Senthilselvan A, Dosman JA, Juorio V, Feddes JJR, Willson P, Classen H, Reynolds SJ, Guenter W, Hurst TS: Respiratory symptoms and reduction in lung function in poultry workers. Can Resp J 2003, 10(7):375-380

11. Schwartz DA, Landas SK, Lassise DL, Burmeister LF, Hunninghake GW, Merchant JA: Airway injury in swine confinement workers. Ann Inter Med 1992, 116:630-635.

12. Charavaryamath C, Singh B: Pulmonary effects of exposure to pig barn air. J Occup Med Toxicol 2006, 1:10. http://www.occup-med.com/content/1/1/10.

13. Crook B, Robertson JF, Travers Glass SA, Botheroyd EM, Lacey J, Topping MD: Airborne dust, ammonia, microorganisms, and antigens in pig confinement houses and the respiratory health of exposed farm workers. Am J Ind Hyg Assoc 1991, 52:271-279.

14. Dosman JA, Graham BL, Hall D, Pahwa P, McDuffie HH, Lucewicz M, To T: Respiratory symptoms and alterations in pulmonary function tests in swine producers in Saskatchewan: Results of a survey of farmers. J Occup Med 1988, 30:715-720.

15. Rylander R, Donham KJ, Hjort C, Brouwer R, Heederik D: Effects of exposure to dust in swine confinement buildings - a working group report. Sand J Work Environ Health 1989, 15:309-312

16. Schwartz DA, Donham KJ, Olenchock SA, Opendorf WJ, Van Esson S, Burmeister LF, Merchant JA: Determinants of longitudinal changes in spirometric function among swine confinement operators and farmers. Am J Rrespir Care Med 1995, 151:47-53.

17. Dosman JA, Lawson JA, Kirychuk SP, Cormier Y, Biem J, Koehncke N: Three new cases of apparent occupational asthma in swine confinement facility employees. Eur Resp J 2006, 28(6):1-2.

18. Kirkhorn S, Garry VF: Agricultural lung diseases. Environ Heal Perspect 2000 108(4):705-712.

19. Alavanja MC, Dosemeci M, Samanic C, Lubin J, Lynch CF, Knott C, Barker J, Hoppin JA, Sandler DP, Coble J, Thomas K, Blair A: Pesticides and lung cancer risk in Agricultural Health Study cohort. Am J Epidemio 2004, 160:876-885.

20. McDuffie HH, Pahwa P, Spinelli JJ, McLaughlin JR, Fincham S, Robson D, Dosman JA, Hu J: Canadian male farm residents, pesticide safety handling practices, exposure to animals and non-Hodgkin's lymphoma (NHL). Am J Ind Med 2002, 42(Suppl 2):54-61.

21. Health Canada: Strategies for Population Health: Investing in the Health of Canadians. Ottawa: Health Canada, Minister of Supply and Services Canada; 1994

22. Pickett W, Day L, Hagel L, Brison RJ, Marlenga BL, Pahwa P, Koehncke N, Crowe T, Snodgrass P, Dosman J: The Saskatchewan Farm Injury Cohort: rationale and methodology. Public Health Reports 2008, 123(5):567-575.

23. Senthilselvan A, McDuffie $H H$, Dosman JA: Association of asthma with use of pesticides: Results of a cross-sectional survey of farmers. Am Rev Respir Dis 1992, 146:884-887.

24. Hoppin JA, Umbach DM, London SJ, Henneberger PK, Kullman GJ, Alavanja MC, Sandler DP: Pesticides and atopic and nonatopic asthma among farm women in the agricultural health study. Am J Respir and Crit Care Med 2008, 177:11-18.

25. Chen Y, Rennie D, Cormier Y, Dosman J: Sex specificity of asthma associated with objectively measured body mass index and waist circumference: The Humboldt Study. Chest 2005, 4:3048-3054.

26. Schwartz DA: Grain dust, endotoxin, and airflow obstruction. Chest 1996, 109:57S-63S.

27. Schwartz D, Thorne PS, Yagla SJ, Burmeister LF, Olenchock SA, Watt IL, Quinn TJ: The role of endotoxin in grain dust-induced lung disease. Am J Respir Crit Care Med 1995, 152:603-608.

28. Michel O, Kips J, Duchateau J, Vertongen F, Robert L, Collect H, Pauwels R, Sergysels R: Severity of asthma is related to endotoxin in house dust. Am J Respir Crit Care Med 1996, 54:1641-1646.

29. Rizzo MC, Naspitz CK, Fernandez-Calda E, LeeKey RF, Mimica I, Sole D: Endotoxin exposure and symptoms in asthmatic children. Pediatr Allergy Immunol 1997, 8:121-126.

30. Park JH, Gold R, Spiegelman DL, Burge HA, Milton DK: House dust endotoxin and wheeze in the first year of life. Am J Respir Crit Care Med 2001, 163:322-328.

31. Rennie D, Chen Y, Lawson J, Dosman J: Differential effects of damp housing on respiratory health in women. J Am Med Women Assoc 2005, 60:46-51.

32. Chen Y, Rennie D, Cormier YF, Dosman JA: Waist circumference is associated with pulmonary function in normal-weight, overweight and obese subjects. Am Soc Nutrition 2007, 85:35-39.

33. Chen $Y$, Dales $R$, Tang M, Krewski D: Obesity may increase the incidence of asthma in women but not in men: longitudinal observations from the Canadian National Population Health Surveys. Am J Epidemiol 2002, 155:191-197.

34. du Plessis V, Beshiri R, Bollman RD, Clemenson H: Definitions of "Rural". Agriculture and Rural Working Paper Series, Working Paper No. 61.Catalogue no. 21-601-MIE- No. 061. Ottawa, Canada: Agricultural Division, Statistics Canada; 2004

35. Statistics Canada: Agricultural Profile of Canada. Ottawa: Minister of Industry 2006

36. Dillman DA: Mail and telephone surveys: The total design method. New York: Wiley; 1978.

37. Dillman DA: Mail and internet surveys: the tailored design method. 2nd edition. New York, NY: Wiley \& Sons Inc; 2000

38. Public Health Agency of Canada: Public Health Approach. What determines health?. [http://www.phac-aspc.gc.ca/ph-sp/phdd/determinants/].

39. Pahwa P, Karunanayake C, Hagel L, Janzen B, Rennie D, Lawson J, Pickett W, Dosman JA: Self-Selection Bias in an Epidemiological Study of Respiratory Health of a Rural Population. J Agromed 2012, 17(3):316-325.

40. Senthilselvan A, Dosman JA, Pahwa P: Respiratory symptoms and alterations in pulmonary tests in poultry producers. Am Rev Resp Dis 1991, 143:A100

41. Chenard L, Senthilselvan A, Grover VK, Kirychuk SP, Lawson J, Hurst TS, Dosman J: Lung function and farm size predict healthy worker effect in swine farmers. Chest 2007, 131(1):245-254.

42. Statement of the American Thoracic Society: Standardization of Spirometry-1987 Update. Am Rev Resp Dis 1987, 136:1285-1298.

43. Crapo RO, Morros AH, Gardner RM: Reference spirometric values for spirometry using techniques and equipment that meet ATS Recommendations. Am Rev Resp Dis 1991, 123:659-664.

44. Senthilselvan A, Rennie D, Chenard L, Burch L, Babiuk L, Schwartz D, Dosman JA: Polymorphisms of toll-like receptor 4 are associated with reduced prevalence of hay fever and atopy. Annals of Asthma Allergy and Immunology 2008, 100:463-468. 
45. Joint Task Force on Practice Parameters, American Academy of Allergy, Asthma and Immunology, American College of Allergy, Asthma and Immunology, Joint Council of Allergy, Asthma and Immunology: Allergen immunotherapy: a practice parameter second update. J Allergy Clin Immunol 2007, 120(suppl 3):S25-S85.

46. Statistics Canada National Population Health Survey Household Component: Documentation for the Derived Variables and the Constant Longitudinal Variables. Accessed on Nov 15, 2012. Available online [http://www.statcan.gc. ca/imdb-bmdi/document/3225_D10_T9_V3-eng.pdf].

47. Feinstein AR: Principles of medical statistics. Boca Raton, Fla: CRC; 2002:503.

48. Eng J: Sample size estimation: how many individuals should be studied? Radiology 2003, 227:309-313.

49. Hsieh FY: Sample size formulae for intervention studies with the cluster as unit of randomization. Statistics in Medicine 1988, 7(11):1195-1201.

50. Kelsey JL, Thompson WD, Evans AS: Methods in observational epidemiology. New York: Oxford University Press; 1986.

51. Rosner B: Fundamentals of biostatistics. 5th edition. Pacific Grove, Calif: Duxbury; 2000:308

52. McCarty C, Chyou P-H, Ziegelbauer L, Kempf D, McCarty D, Gunderson P, Reding D: A Comparison of Cardiovascular Disease Risk Factors in Farm and Non-farm Residents: the Wisconsin Rural Women's Health Study. Wisconsin Medical Journal 2002, 101(7):34-39.

53. Curwin BD, Hein MJ, Sanderson WT, Striley C, Heederik D, Kromhout H, Reynolds SJ, Alavanja MC: Pesticide dose estimates for children of lowa farmers and non-farmers. Environ Res 2007, 105:307-315

54. Curwin BD, Hein MJ, Sanderson WT, Striley C, Heederik D, Kromhout $H$ Reynolds SJ, Alavanja MC: Urinary Pesticide Concentrations Among Children, Mothers and Fathers Living in Farm and non-Farm Housholds in lowa. Am Occup Hyg 2007, 51(1):53-65.

55. Stiefelmeyer K: Income and wealth in Canada: Farm and Non-farm households. Advancing a Policy Dialogue- Series 1: Understanding the structure of Canadian farm income. Ottawa, ON: Canadian Agri-Food Policy Institute; 2011:18-21. Accessed on May 31, 2012. Available online [http://www.capiicpa.ca/destinations/CAPI_AdvancingPolicyDialogue.pdf].

56. Himes $\mathrm{CL}$, Rutrough TS: Differences in the Use of Health Services by Metropolitan and Nonmetropolitan Elderly. J Rural Heal 1994, 10(2):80-88.

57. Hox JJ, De Leeuw ED: A comparison of nonresponse in mail, telephone and face-to-face surveys: Applying multilevel modeling to meta-analysis. Qual Quant 1994, 28:329-344.

doi:10.1186/1756-0500-5-400

Cite this article as: Pahwa et al:: The Saskatchewan rural health study: an application of a population health framework to understand respiratory health outcomes. BMC Research Notes 2012 5:400.

\section{Submit your next manuscript to BioMed Central and take full advantage of:}

- Convenient online submission

- Thorough peer review

- No space constraints or color figure charges

- Immediate publication on acceptance

- Inclusion in PubMed, CAS, Scopus and Google Scholar

- Research which is freely available for redistribution

Submit your manuscript at www.biomedcentral.com/submit

C Biomed Central 